\title{
Safety of a bivalent, killed, whole-cell oral cholera vaccine in pregnant women in Bangladesh: evidence from a randomized placebo-controlled trial
}

Ashraful Islam Khan ${ }^{1}$, Mohammad Ali², Julia Lynch³, Alamgir Kabir ${ }^{3}$, Jean-Louis Excler ${ }^{3}$, Md. Arifuzzaman Khan', Md. Taufiqul Islam¹, Afroza Akter', Fahima Chowdhury', Amit Saha', Iqbal Ansary Khan', Sachin N. Desai', Deok Ryun Kim³ ${ }^{3}$ Nirod Chandra Saha ${ }^{1}$, Ajit P. Singh ${ }^{3}$, John D. Clemens ${ }^{1}$ and Firdausi Qadri ${ }^{*}$

\begin{abstract}
Background: Cholera increases the risk of harmful effects on foetuses. We prospectively followed pregnant women unaware of their pregnancy status who received a study agent in a clinical trial evaluating the association between exposure to an oral cholera vaccine (OCV) and foetal survival.

Methods: Study participants were selected from a randomized placebo-controlled trial conducted in Dhaka, Bangladesh. The vaccination campaign was conducted between January 10 and February 4, 2014. We enrolled women who were exposed to an OCV or placebo during pregnancy (Cohort 1) and women who were pregnant after the vaccination was completed (Cohort 2). Our primary endpoint was pregnancy loss (spontaneous miscarriage or stillbirth), and the secondary endpoints were preterm delivery and low birth weight. We employed a log-binomial regression to calculate the relative risk of having adverse outcomes among OCV recipients compared to that among placebo recipients.

Result: There were 231 OCV and 234 placebo recipients in Cohort 1 and 277 OCV and 299 placebo recipients in Cohort 2. In Cohort 1, the incidence of pregnancy loss was 113/1000 and 115/1000 among OCV and placebo recipients, respectively. The adjusted relative risk for pregnancy loss was 0.97 ( $95 \% \mathrm{Cl}: 0.58-1.61 ; p=0.91)$ in Cohort 1. We did not observe any variation in the risk of pregnancy loss between the two cohorts. The risks for preterm delivery and low birth weight were not significantly different between the groups in both cohorts.
\end{abstract}

Conclusions: Our study provides additional evidence that exposure to an OCV during pregnancy does not increase the risk of pregnancy loss, preterm delivery, or low birth weight, suggesting that pregnant women in cholera-affected regions should not be excluded in a mass vaccination campaign.

Trial registration: The study is registered at (http://clinicaltrials.gov). Identifier: NCT02027207.

Keywords: OCV, Cholera, Pregnant women, Safety, Bangladesh

\footnotetext{
* Correspondence: fqadri@icddrb.org

${ }^{1}$ International Centre for Diarrhoeal Disease Research Bangladesh (icddr,b),

68, Shaheed Tajuddin Ahmed Sarani, Mohakhali Dhaka 1212, Bangladesh

Full list of author information is available at the end of the article
}

(c) The Author(s). 2019 Open Access This article is distributed under the terms of the Creative Commons Attribution 4.0 International License (http://creativecommons.org/licenses/by/4.0/), which permits unrestricted use, distribution, and reproduction in any medium, provided you give appropriate credit to the original author(s) and the source, provide a link to the Creative Commons license, and indicate if changes were made. The Creative Commons Public Domain Dedication waiver (http://creativecommons.org/publicdomain/zero/1.0/) applies to the data made available in this article, unless otherwise stated. 


\section{Background}

Cholera remains a fatal disease in resource-limited countries, which is caused by Vibrio cholerae 01 or 0139 that spreads by water and food contaminated with human faeces. If the infected individuals do not promptly receive adequate treatment, the risk of death can be up to $70 \%$ [1]. Cholera during pregnancy may have an adverse effect on pregnancy outcome [2,3]. The effect of cholera on pregnancy outcome has been observed since the nineteenth century [4]. Much of the published literature on cholera during pregnancies reported pregnancy loss, with the magnitude varying from 2 to $36 \%$ [2, 5-9]. A recent study from Haiti reported that pregnant women with severe dehydrating cholera had 9.4 times more risk of delivering a foetal death compared to those with mild dehydrating cholera [10].

A killed whole-cell oral cholera vaccine (OCV) is currently being used as a major tool to control and prevent cholera [11-14]. Theoretically, an OCV should not produce any adverse pregnancy outcomes due to its inability to replicate in the gut and oral route of intake. The World Health Organization (WHO) recommends that pregnant women be included in OCV campaigns because evidence indicates high potential benefit and minimal risks [15]. A mass vaccination campaign conducted in Zanzibar, Tanzania in 2009 with an OCV, Dukoral, did not cause any harmful effects on pregnancies [16]. A retrospective cohort study performed in Guinea in 2013 also showed no evidence of an increased risk of pregnancy loss after receiving Shanchol [17]. Recently, a retrospective study conducted in Bangladesh and a prospective study conducted in Malawi did not find any harmful effects of an OCV in pregnant women $[18,19]$. However, the package insert for OCVs still recommends caution for use during pregnancy due to limited safety data in this population group. Since most of the studies were carried out in African countries during cholera outbreaks, more evidence is needed from cholera endemic areas, in particular, from parts of the world known to have a high prevalence of cholera.

We conducted an individually randomized, placebocontrolled trial of a single-dose regimen of the OCV Shanchol. As per the package insert for Shanchol, individuals 1 year or older and non-pregnant were invited to participate in the trial. All married women of childbearing age (13-49 years) were verbally screened for pregnancy before dosing. Since pregnancy in the first trimester may not be visible or some women may experience irregular menstruation, several pregnant women took a study agent unaware of their pregnancy status at the time of dosing. In this study, we evaluated the effect of vaccination on pregnant women who were unaware of their pregnancy status and who inadvertently received an OCV. The main goal of this study was to evaluate the effect of vaccination on pregnant women who received the OCV without knowing their pregnancy status.

\section{Methods \\ Study population}

The clinical trial was conducted in an urban setting in Dhaka, Bangladesh, where cholera is highly endemic [20]. A total of 204,700 residents in the area underwent randomization and received a single dose of OCV. A baseline census was conducted during November 12, 2012 and January 29, 2013 to enumerate the regular residents in the study area. This census was updated immediately before the initiation of vaccine administration in 2014. Details of the study area, randomization, and the study procedure were published elsewhere [20]. In this analysis, we considered only the women of childbearing age who had received study agents.

\section{Mass vaccination campaign}

The mass vaccination campaign was conducted from 10 January 2014 to 4 February 2014 with technical assistance from the Expanded Programme on Immunization (EPI) of the Ministry of Health and Social Welfare, City Corporation, International Vaccine Institute (IVI) and other stakeholders. The study agents were offered to the eligible subjects in an individually randomized fashion. Each dose of vaccine or placebo was $1.5 \mathrm{ml}$ in volume. Placebo vials contained only the inert constituents starch and xanthan gum. The study agents were dispensed in liquid form in identical vials in a double-blind manner. The details of the composition of the OCV were described previously [12]. Since it was not feasible to perform a pregnancy test during the vaccination campaign, the pregnancy status and date of the last menstrual period (LMP) were inquired verbally for all married women of childbearing age (13-49 years) prior to vaccination. If the date of the LMP was more than 4 weeks, irregular periods, unknown, or uncertain, we considered them ineligible for vaccination.

\section{Enrolment of study subjects and follow-up}

During the screening visit, between the 22nd of April and 10th of July 2014 (approximately 3-5 months after the vaccination campaign was completed), trained female field staff screened the pregnancy status of all women of childbearing age receiving the study agents. After obtaining verbal consent, a structured questionnaire was used in the interviews. A household was visited a maximum of 3 times if a potential woman was found absent. If a woman was not sure about her pregnancy or could not confirm her pregnancy status during the visit, she was re-visited 1 month later. After confirmation of the pregnancy status of the potential women, 
the field staff notified this result to the study physicians with the list of pregnant women for enrolment in the study and further follow-up. Scheduled monthly phone calls were made to each participant to inquire about the pregnancy status until 6 months of her gestational age. If a pregnancy outcome was notified during the screening visit, this report was considered a retrospective follow-up. The study physicians interviewed the woman about the outcome of her pregnancy after obtaining written informed consent. If women were found pregnant (whose outcome had not occurred), they were termed prospective follow-up.

From 6 months of gestational age, each participant was followed until miscarriage, stillbirth or end of pregnancy. The study physicians conducted monthly home visits for the follow-up interviews. Informed written consent was obtained from the participants prior to the initial interview. In the case of minor participants, consent was obtained from the parents or guardians on the same consent form. Detailed information on pregnancy, such as obstetrical history and clinical history, including anthropometrical measurement (height, weight and mid-upper arm circumference), was collected from the participants. Physicians' contact numbers were given to the participants for notifying them if the subjects would change their current address or if any outcome occurred before the next visit. Weekly phone calls were made after 8 months of gestational age. A final home visit was made within 1 week after pregnancy outcome when anthropometrical measurements (height, weight) of the live newborn were taken. Moreover, adverse pregnancy outcomes (pregnancy loss or any congenital anomalies) were recorded immediately after the event.

\section{Data analysis}

In the primary analysis, we included women who were pregnant during vaccination whose foetuses were exposed to a study agent (Cohort 1), and in the secondary analysis, we included women who became pregnant just after vaccination whose foetuses were not exposed to a study agent (Cohort 2). We compared the characteristics of the vaccine and placebo recipients using the chi-squared test (or Fisher's exact test for sparse data) and Student's t-test (or Mann-Whitney's test for non-normal data) for binary and continuous variables, respectively, for each cohort. The primary endpoint was pregnancy loss (spontaneous miscarriage or stillbirth). We defined spontaneous miscarriage as termination of a pregnancy without a known external cause prior to 28 weeks of gestation [21], and stillbirth was defined as delivery of a dead foetus at 28 weeks or later [22]. The secondary endpoints were preterm delivery (defined by pregnancy ending with a live birth $<37$ weeks of gestational age) and low birth weight (birth weight $<2500 \mathrm{~g}$ ).
We also performed a supplementary analysis assessing a potential effect of an OCV on induced or accidental abortion.

We used a log-binomial model and calculated relative risk (RR) after adjusting for potential confounders. The confounders were selected from the bivariate analysis, which appeared imbalanced between vaccine and placebo recipients at $p<0.20$ and following the rule of 10 events per covariate to maximize the coverage of the confidence interval of the estimate from a regression model [23]. The strength of the relationship of one over the other covariates was used in selecting the covariates when following the rule of 10 events per covariate. All $p$-values and 95\% confidence intervals were interpreted in a two-tailed fashion. All analysis was performed in $\mathrm{R}$ version 3.2.3 (Vienna, Austria, 2016).

\section{Result}

A total of 204,700 individuals participated in the clinical trial, of whom 71,202 were women of reproductive age (13-49 years). During the screening visit, we identified 1323 pregnancies. Among them, we could recruit 550 pregnant women in Cohort 1 and 773 in Cohort 2. We lost to follow-up 41 women in Cohort 1 and 76 women in Cohort 2 between vaccination and screening visits. Due to induced or accidental abortion, we excluded 44 women in Cohort 1 and 121 women in Cohort 2. Finally, we analysed 465 women in Cohort 1 and 576 women in Cohort 2. We prospectively followed 405 (87\%) of 465 women in Cohort 1 and 535 (93\%) of 576 women in Cohort 2, and the rest were followed retrospectively (Fig. 1).

There were 231 OCV recipients and 234 placebo recipients in Cohort 1 and 277 OCV and 299 placebo recipients in Cohort 2. Socio-demographic, nutritional, and obstetric characteristics of the pregnant women were balanced between OCV recipients and placebo recipients except for having diarrhoea in the past 6 months prior to registration in the baseline census among women in Cohort 2 (Table 1). In Cohort 1, there were 26 adverse pregnancy outcomes in the OCV group and 27 in the placebo group. In this cohort, the incidence rate of an adverse pregnancy outcome was 112.6 per 1000 pregnancies among OCV recipients and 115.4 per 1000 pregnancies among placebo recipients (Table 2). Incidence of preterm delivery was 33.8, and of low birth weight was 97.6 per 1000 live births among OCV recipients, and 58.0 and 111.1, respectively, among the placebo recipients. The risk of having an adverse pregnancy outcome among women exposed to the OCV was 0.97 (95\% CI: $0.58-1.61, p=0.907)$ compared to that of women exposed to placebo. No significant risk was observed for having a preterm delivery or low birth weight 


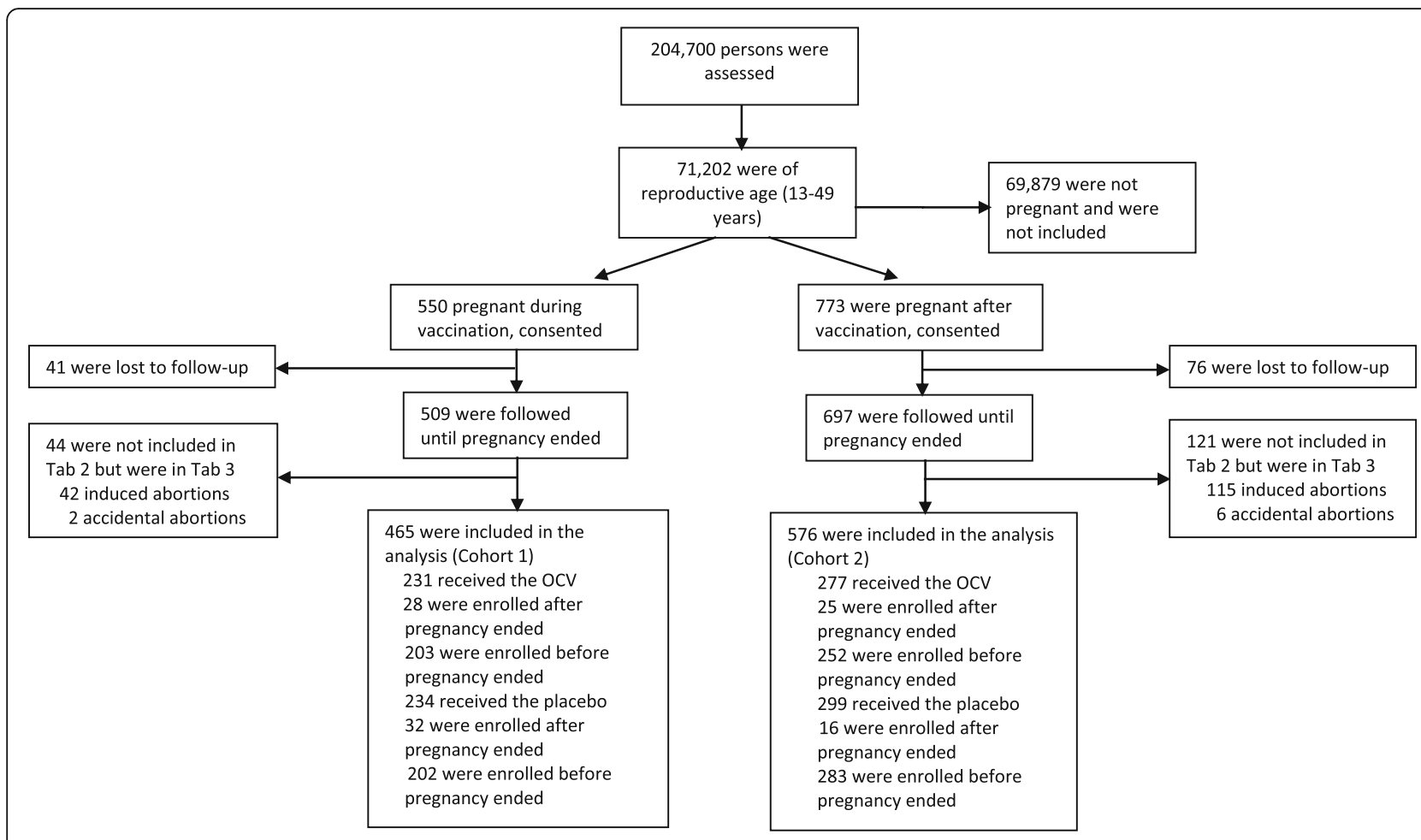

Fig. 1 Assembling the study population for analysis

among women exposed to the OCV compared to those of the placebo recipients (Table 2).

In Cohort 2, there were 39 adverse pregnancy outcomes in each of the study groups. The incidence rate of an adverse pregnancy outcome in this cohort was 140.8 per 1000 pregnancies among OCV recipients and 130.4 per 1000 pregnancies among placebo recipients (Table 2). The rate of preterm delivery was 50.4 and of low birth weight was 79.8 per 1000 live births in OCV recipients and 80.8 and 100.0, respectively, in placebo recipients. There were a total of 26 adverse pregnancy outcomes, including 20 miscarriages and 6 stillbirths in Cohort 1. In Cohort 2, there were 32 miscarriages, and 7 still births occurred. There was also no statistically significant difference in the risk of pregnancy loss among OCV recipients in Cohort 2 compared to that among placebo recipients of this cohort, and the rates of preterm delivery and low birth weight were similar between the two groups of this cohort (Table 2).

Table 3 presents the effect of an OCV on induced or accidental abortion. Among women pregnant during vaccination $(n=509)$, the rates of induced or accidental abortion were 83.3 and 89.5 per 1000 pregnancies among OCV and placebo recipients, respectively. The risk of induced or accidental abortion was not significant $[R R=0.93,95 \% \mathrm{CI}$ : $0.52-1.64]$. Among women pregnant after vaccination ( $n$ $=697$ ), the rates of induced or accidental abortion were
178.0 and 169.4 per 1000 pregnancies among OCV and placebo recipients, respectively. We found no risk due to the $\mathrm{OCV}$ on induced or accidental abortion $[R R=1.05$, 95\% CI: 0.76-1.45].

\section{Discussion}

The results of our study suggest that administration of an OCV during pregnancy was not associated with adverse pregnancy outcomes. Although not statistically significant, the rate of adverse pregnancy outcomes among the OCV recipients was slightly lower compared to that among the placebo recipients. There were a total of 26 adverse pregnancy outcomes, including 20 miscarriages and 6 stillbirths in Cohort 1. In Cohort 2, there were 32 miscarriages, and 7 still births occurred. Previously reported studies in pregnant women receiving an OCV have observed a non-significant increase in adverse pregnancy outcomes among women receiving the OCV $[16$, 17]. Unlike those studies, our samples were taken from an individually randomized trial population; therefore, it is less likely that our results are biased by sample selection. Additionally, the different adverse pregnancy outcome rates (miscarriage and stillbirth) were also similar between OCV and placebo recipients, suggesting that an OCV (killed, non-replicating, oral administration) does not have any impact on foetus survival. Our results reinforce previous findings that OCVs do not have any 
Table 1 Socioeconomic and obstetric characteristics of the OCV recipients and placebo recipients among pregnant women

\begin{tabular}{|c|c|c|c|c|c|c|}
\hline \multirow[t]{2}{*}{ Characteristics } & \multicolumn{3}{|c|}{ Pregnant during vaccination (Cohort 1) } & \multicolumn{3}{|c|}{ Pregnant after vaccination (Cohort 2) } \\
\hline & $\begin{array}{l}\text { OCV recipients } \\
(n=231)\end{array}$ & $\begin{array}{l}\text { Placebo recipients } \\
(n=234)\end{array}$ & $\begin{array}{l}\mathrm{p}- \\
\text { value }\end{array}$ & $\begin{array}{l}\text { OCV recipients } \\
(n=277)\end{array}$ & $\begin{array}{l}\text { Placebo recipients } \\
(n=299)\end{array}$ & $p$-value \\
\hline $\begin{array}{l}\text { Median gestational age at screening visit/ } \\
\text { recruitment- (IQR; weeks) }\end{array}$ & $22(19,25)$ & $21(19,25.5)$ & 0.541 & $12(9,15)$ & $12(9,16)$ & 0.751 \\
\hline $\begin{array}{l}\text { Median gestational age at vaccination - (IQR; } \\
\text { weeks) }\end{array}$ & $4(1.79,7.71)$ & $4.43(2.14,8.57)$ & 0.407 & - & - & - \\
\hline $\begin{array}{l}\text { Median time of vaccination prior to pregnancy } \\
-(\text { IQR; weeks) }\end{array}$ & - & - & - & $4.71(2.14,8.14)$ & $5(2.43,8.29)$ & 0.408 \\
\hline Exposed to the OCV in the 1st trimester- no. (\%) & $198(85.71)$ & $194(82.91)$ & 0.481 & & & \\
\hline Mean age (SD; year) & $26.27(5.70)$ & $26.19(5.70)$ & 0.876 & $24.92(5.10)$ & $24.81(5.26)$ & 0.785 \\
\hline Illiterate- no. (\%) & $53(22.94)$ & $49(20.94)$ & 0.682 & $39(14.08)$ & $54(18.06)$ & 0.236 \\
\hline $\begin{array}{l}\text { Diarrhoea within past } 6 \text { months prior to baseline } \\
\text { census-- no. (\%) }\end{array}$ & $24(10.39)$ & $28(11.97)$ & 0.695 & $31(11.19)$ & $16(5.35)$ & 0.016 \\
\hline Live in own house - no. (\%) & $37(16.02)$ & $34(14.53)$ & 0.751 & $59(21.30)$ & $62(20.74)$ & 0.949 \\
\hline Live in a household with family size $\leq 4-$ no. (\%) & $112(48.48)$ & $108(46.15)$ & 0.681 & $112(40.43)$ & $106(35.45)$ & 0.252 \\
\hline $\begin{array}{l}\text { Live in a household using own tap as the source } \\
\text { of drinking water-- no. (\%) }\end{array}$ & $15(6.49)$ & $13(5.56)$ & 0.818 & $18(6.50)$ & $31(10.37)$ & 0.130 \\
\hline $\begin{array}{l}\text { Live in a household with treated drinking water-- } \\
\text { no. (\%) }\end{array}$ & $127(54.98)$ & $133(56.84)$ & 0.756 & $177(64.13)$ & $189(63.21)$ & 0.887 \\
\hline Live in a household using sanitary toilet- no. (\%) & $156(67.53)$ & $167(71.37)$ & 0.425 & $214(77.26)$ & $219(73.24)$ & 0.309 \\
\hline $\begin{array}{l}\text { Median time living in the household (IQR; } \\
\text { months) }\end{array}$ & $20(7,48)$ & $15(6,38.5)$ & 0.369 & $24(10,48)$ & $24(6,48)$ & 0.683 \\
\hline Live in a household with concrete roof - no. (\%) & $37(16.02)$ & $31(13.25)$ & 0.475 & $48(17.33)$ & $70(23.41)$ & 0.088 \\
\hline Live in a household with concrete wall - no. (\%) & $161(69.70)$ & $160(68.38)$ & 0.835 & $205(74.01)$ & $212(70.90)$ & 0.460 \\
\hline $\begin{array}{l}\text { Live in a household using shared kitchen- } \\
\text { no. (\%) }\end{array}$ & $197(85.28)$ & $202(86.32)$ & 0.850 & $232(83.75)$ & $253(84.62)$ & 0.866 \\
\hline Live in a household using shared toilet- no. (\%) & $206(89.18)$ & $216(92.31)$ & 0.315 & $242(87.36)$ & $258(86.29)$ & 0.796 \\
\hline Live in a household with only one room- no. (\%) & $54(23.38)$ & $54(23.08)$ & 1.000 & $82(29.60)$ & $77(25.75)$ & 0.347 \\
\hline \multicolumn{7}{|l|}{ Obstetric history } \\
\hline Had any ANC visit ${ }^{\mathrm{a}}-$ no. (\%) & $191(82.68)$ & $189(80.77)$ & 0.679 & $246(88.81)$ & $267(89.30)$ & 0.957 \\
\hline Had ankle swelling- no. (\%) & $11(4.76)$ & $18(7.69)$ & 0.265 & $15(5.42)$ & $18(6.02)$ & 0.894 \\
\hline Had gestational diabetes ${ }^{\mathrm{b}}-$ no. (\%) & $4(1.73)$ & $2(0.85)$ & 0.448 & $1(0.36)$ & $4(1.34)$ & 0.375 \\
\hline Had gestational hypertensionc ${ }^{c}$ no. (\%) & $1(0.43)$ & $4(1.71)$ & 0.372 & $4(1.44)$ & $8(2.68)$ & 0.387 \\
\hline Had eclampsia'd- no. (\%) & $1(0.43)$ & $0(0.00)$ & 0.497 & $3(1.08)$ & $1(0.33)$ & 0.356 \\
\hline Had history of stress ${ }^{\mathrm{e}}-$ no. (\%) & $26(11.26)$ & $23(9.83)$ & 0.726 & $29(10.47)$ & $38(12.71)$ & 0.479 \\
\hline Had previous bad obstetrical history ${ }^{f}-$ no. (\%) & $78(33.77)$ & $76(32.48)$ & 0.844 & $102(36.82)$ & $115(38.46)$ & 0.749 \\
\hline Had any chronic disease ${ }^{7}-$ no. (\%) & $9(3.90)$ & $6(2.56)$ & 0.582 & $11(3.97)$ & $12(4.01)$ & 1.000 \\
\hline $\begin{array}{l}\text { Mid-upper arm circumference } \leq 21.5 \mathrm{~cm}- \\
\text { no. (\%) }\end{array}$ & $11(6.36)$ & $11(6.79)$ & 1.000 & $11(4.76)$ & $13(5.20)$ & 0.991 \\
\hline \multicolumn{7}{|c|}{ 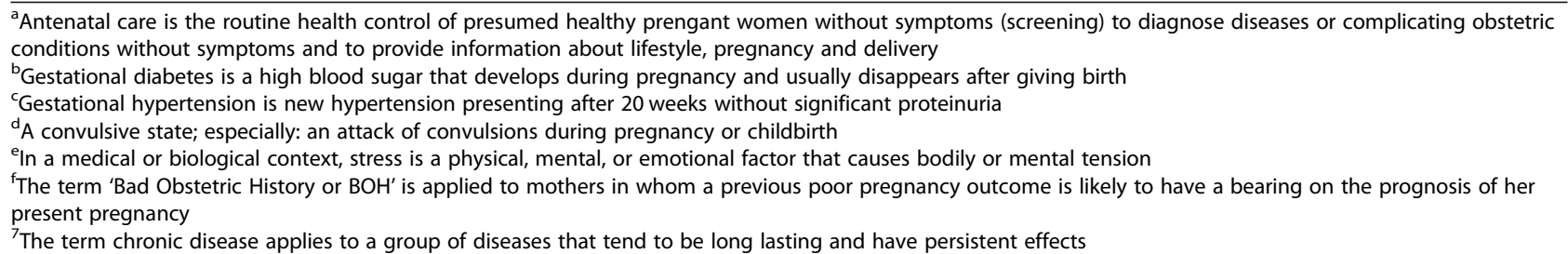 } \\
\hline
\end{tabular}

negative impact on preterm delivery, low birth weight or congenital anomalies. Based on several studies, the WHO recommends that an OCV be given to women who are pregnant $[18,19,24]$. Altogether, these data suggest that an $\mathrm{OCV}$ can be administered during pregnancy. 
Table 2 Relative risk (RR) of having an adverse pregnancy outcome among OCV recipients compared to that of placebo recipients

\begin{tabular}{|c|c|c|c|c|c|c|}
\hline \multirow[t]{2}{*}{ Pregnancy outcome } & \multicolumn{2}{|l|}{ OCV recipients } & \multicolumn{2}{|l|}{ Placebo recipients } & \multirow[t]{2}{*}{ Crude RR (95\% Cl, $p$-value) } & \multirow[t]{2}{*}{ Adj. RR (95\% Cl, p-value) } \\
\hline & Cases/ Population & Rate/1000 & Cases/ Population & Rate/1000 & & \\
\hline \multicolumn{7}{|c|}{ Pregnant during vaccination (Cohort 1) } \\
\hline Adverse pregnancy outcome & $26 / 231$ & 112.6 & $27 / 234$ & 115.4 & $0.98(0.58-1.62,0.923)$ & $0.97^{\mathrm{a}}(0.58-1.61,0.907)$ \\
\hline Miscarriage & $20 / 231$ & 86.6 & $22 / 234$ & 94.0 & $0.92(0.51-1.64,0.780)$ & $0.91^{\mathrm{a}}(0.51-1.63,0.752)$ \\
\hline Stillbirth & $6 / 211$ & 28.4 & $5 / 212$ & 23.6 & $1.21(0.37-4.13,0.754)$ & $-{ }_{-}^{d}$ \\
\hline Preterm delivery & $7 / 207$ & 33.8 & $12 / 207$ & 58.0 & $0.59(0.22-1.43,0.255)$ & $0.58^{\mathrm{a}}(0.22-1.40,0.237)$ \\
\hline Low birth weight & $20 / 205$ & 97.6 & $23 / 207$ & 111.1 & $0.88(0.49-1.55,0.653)$ & $0.88^{\mathrm{a}}(0.49-1.55,0.656)$ \\
\hline \multicolumn{7}{|l|}{ Pregnant after vaccination (Cohort 2) } \\
\hline Adverse pregnancy outcome & $39 / 277$ & 140.8 & $39 / 299$ & 130.4 & $1.08(0.71-1.63,0.717)$ & $1.02^{\mathrm{b}}(0.67-1.55,0.930)$ \\
\hline Miscarriage & $36 / 277$ & 130.0 & $32 / 299$ & 107.0 & $1.21(0.78-1.91,0.395)$ & $1.15^{\mathrm{b}}(0.73-1.81,0.555)$ \\
\hline Still birth & $3 / 241$ & 12.4 & $7 / 267$ & 26.2 & $0.47(0.10-1.69,0.276)$ & $-{ }_{-}^{d}$ \\
\hline Preterm delivery & $12 / 238$ & 50.4 & $21 / 260$ & 80.8 & $0.62(0.30-1.22,0.179)$ & $-{ }^{d}$ \\
\hline Low birth weight & $19 / 238$ & 79.8 & $26 / 260$ & 100.0 & $0.80(0.45-1.40,0.434)$ & $0.82^{\complement}(0.46-1.43,0.477)$ \\
\hline
\end{tabular}

${ }^{a}$ Adjusted for gestational age at vaccination

${ }^{\mathrm{b}}$ Adjusted for time of vaccination prior to pregnancy (included by choice due to biological plausibility), diarrhoea in past 6 months and roof material of household

c Adjusted for diarrhoea in the past 6 months

${ }^{\mathrm{d}}$ Number of cases was not sufficient to perform a multivariable model

In our study, we observed that the miscarriage and stillbirth rates were comparable in both cohorts. In a survey conducted between during 1982 and 2002 in a rural area approximately $55 \mathrm{~km}$ southeast of Dhaka, we observed 53 miscarriages per 1000 pregnancies and 30 stillbirths per 1000 births [21]. In another study conducted in northwest Bangladesh during 2001 and 2007, 88 miscarriages per 1000 pregnancies were observed, using a miscarriage definition of $<24$ weeks of gestation [25]. According to a recent report, there are 19 stillbirths per 1000 births in Bangladesh [22]. These data suggest that the rate of adverse pregnancy outcomes differs by the setting and by the method of detection in Bangladesh and may vary over time. In addition, it remains difficult to categorize abortion as induced or spontaneous because of legal and moral loopholes. Under the penal code of 1860, induced abortion is illegal in Bangladesh except when performed to save a women's life.

Cholera causes maternal dehydration during pregnancy, which leads to critical hypovolemia that compromises placental and foetal perfusion and eventually leads to foetal death [24]. As a result, miscarriage or premature delivery may occur. Moreover, different studies have reported that pregnancy may be associated with poor outcomes in cases of delayed rehydration therapy $[2,10]$. Women who reported having had cholera while they were pregnant were at 6 -fold higher risk of miscarriage and 3-fold higher risk of having a stillborn child than women who did not have cholera [17]. Data from Senegal demonstrated that pregnant women took four times longer to reach a health facility for cholera treatment than the general population [9]. Therefore, preventive measures such as vaccination could be a better choice to prevent cholera during pregnancy, which will reduce the risk of pregnancy loss.

The unique strength of our study is that we drew our samples from a double-blinded randomized study, suggesting that the results of our study are free from sampling bias. We initiated screening immediately after vaccination and could capture many participants (84\%) receiving the $\mathrm{OCV}$ in their 1st trimester. We also followed the participants prospectively, which minimizes recall bias. The follow-ups were made by trained physicians to correctly classify pregnancy outcomes.

However, our study had some limitations. First, our study was conducted in an endemic setting where

Table 3 Relative risk of having an abortion (induced or accidental) among OCV recipients compared to that of placebo recipients

\begin{tabular}{|c|c|c|c|c|c|}
\hline \multirow[t]{2}{*}{ Pregnancy outcome } & \multicolumn{2}{|l|}{ OCV recipients } & \multicolumn{2}{|l|}{ Placebo recipients } & \multirow[t]{2}{*}{ Crude RR ( $95 \% \mathrm{Cl}, p$-value) } \\
\hline & Cases/ Population & Rate/1000 & Cases/ Population & Rate/1000 & \\
\hline \multicolumn{6}{|c|}{ Pregnant during vaccination } \\
\hline Abortion & $21 / 252$ & 83.33 & $23 / 257$ & 89.5 & $0.93(0.52-1.64,0.805)$ \\
\hline \multicolumn{6}{|c|}{ Pregnant after vaccination } \\
\hline Abortion & $60 / 337$ & 178.0 & $61 / 360$ & 169.4 & $1.05(0.76-1.45,0.765)$ \\
\hline
\end{tabular}


several subjects may have developed some preexisting immunity. Although there is no clear knowledge of the effect of preexisting immunity of $\mathrm{OCV}$ recipients on foetal survival, our results may not apply in non-endemic settings. Evidence from the studies conducted in the past is not different from our results, suggesting that the pregnancy outcomes among $\mathrm{OCV}$ recipients are not influenced by the type of setting. Second, although our aim was to conduct a prospective study, $10 \%$ of pregnancies were already terminated at the time of recruitment. Since a large proportion of the women were prospectively followed and the number of women retrospectively followed was similar in both groups, we do not think that the small proportion of the retrospectively followed women affected the analysis. Third, we tested only a single dose, whereas the recommended dose of an OCV is a double dose. Another potential limitation is that we did not find any congenital anomalies of the infants. However, the expected prevalence of congenital anomalies among newborns is approximately $2 \%$ [26], and the probability of not detecting such defects by chance is $8 \%$ (calculated from a binomial distribution with 500 trials).

Due to insufficient safety data, cholera vaccination campaigns frequently exclude pregnant women based on information in package inserts of the OCV. However, according to the WHO, individuals who are at risk of cholera and for whom vaccines are not contraindicated should be targeted by the OCV. Many inactivated vaccines are already given to pregnant women, including tetanus, diphtheria, hepatitis $\mathrm{B}$, flu, and pneumococcal vaccines [27], whereas the OCV used in this study is also an inactivated killed vaccine given orally and acts locally in the intestine [28].

\section{Conclusion}

Women in an endemic or outbreak setting are at risk of cholera, and contraction of the disease during pregnancy can cause miscarriages or stillbirths [3]. Our study confirms that there was no risk of foetal loss due to receiving an $\mathrm{OCV}$ during pregnancy. Therefore, when the risk of cholera infection is high, an OCV should be offered to pregnant women since they are particularly at a high risk of losing their foetus if they become infected with cholera.

\section{Abbreviations}

EPI: Expanded Programme on Immunization; IVI: International Vaccine Institute; LMP: last menstrual period; OCV: Oral cholera vaccine; RR: relative risk; WHO: World Health Organization

\section{Acknowledgements}

The icddr,b is thankful to the Governments of Australia, Bangladesh, Canada, Sweden, and the UK for providing core or unrestricted support. We thank the people of Mirpur where our study is being undertaken, the field, laboratory, and data management staff who made tremendous efforts to make the study successful, and the people who provided valuable support to our study.

\section{Funding}

This study was supported by the International Vaccine Institute with funding from the Bill \& Melinda Gates Foundation (OPP52797). The study was also supported by core grants to the icddr,b. The funders had no role in data collection, data analysis, data interpretation, or writing of this report.

\section{Availability of data and materials}

The corresponding author had full access to all of the data in the study and had final responsibility for the decision to submit the manuscript for publication. Materials described in the manuscript, including all relevant data, will be freely available to any scientist wishing to use them for non-commercial purposes, without breaching participant confidentiality through requesting to this email: ashrafs@icddrb.org

\section{Authors' contributions}

AIK and MA contributed to the study design. AIK, MAK, MTI, JL, JE, SND, APS, AA, FC, AS, IAK, NCS, JC and FQ contributed to the implementation and supervision of the study. AIK, MA, DRK and AK analysed the data and took responsibility for the accuracy of the data analysis. All authors participated in the writing of the report, read and approved the final version.

\section{Ethics approval and consent to participate}

The study was approved by the Research Review Committee and the Ethical Review Committee of the icddr,b, Dhaka, Bangladesh, and the Institutional Review Board of the International Vaccine Institute. A data safety monitoring board also approved the study and monitored the progress of work. Written informed consent was obtained from all participants. In the case of minor participants, consent was obtained from the parents or guardians on the same consent form. The study is registered at (http://clinicaltrials.gov). Identifier: NCT02027207; 23 / 12 / 2013.

\section{Consent for publication}

Not applicable.

\section{Competing interests}

The authors declare that they have no competing interests.

\section{Publisher's Note}

Springer Nature remains neutral with regard to jurisdictional claims in published maps and institutional affiliations.

\section{Author details}

${ }^{1}$ International Centre for Diarrhoeal Disease Research Bangladesh (icddr,b), 68, Shaheed Tajuddin Ahmed Sarani, Mohakhali Dhaka 1212, Bangladesh. ${ }^{2}$ Johns Hopkins Bloomberg School of Public Health, Baltimore, MD, USA.

${ }^{3}$ International Vaccine Institute, Seoul, South Korea.

Received: 7 February 2018 Accepted: 22 April 2019

Published online: 15 May 2019

\section{References}

1. Lindenbaum J, Greenough WB, Islam M. Antibiotic therapy of cholera in children. Bull World Health Organ. 1967;37(4):529.

2. Hirschhorn N, Chowdhury AA, Lindenbaum J. Cholera in pregnant women. Lancet. 1969;293(7608):1230-2.

3. Tran N-T, et al. Cholera in pregnancy: a systematic review and meta-analysis of fetal, neonatal, and maternal mortality. PLoS One. 2015;10(7):e0132920.

4. Proegler C. Cholera, and its relation to pregnancy and child-birth. Boston Med Surg J. 1871:85(13):200-2.

5. Khan P. Asiatic cholera in pregnancy. Int Surg. 1969;51(2):138-41.

6. Ayangade $\mathrm{O}$. The significance of cholera outbreak in the prognosis of pregnancy. Int J Gynecol Obstet. 1981;19(5):403-7.

7. Saona P, et al. Cólera en gestantes en el Hospital Nacional Cayetano Heredia, Lima-Perú. Rev méd hered. 1991;2(3):112-6.

8. Grados P. Battilana CA. El tratamiento de la diarrea coleriforme en la gestación; 1994.

9. Diop S, et al. Cholera and pregnancy: epidemiological, clinical, and evolutionary aspects. Med Maladies Infectieuses. 2007;37(12):816-20. 
10. Ciglenecki I, et al. Cholera in pregnancy: outcomes from a specialized cholera treatment unit for pregnant women in Léogâne, Haiti. PLoS Negl Trop Dis. 2013;7(8):e2368.

11. Qadri F, et al. Feasibility and effectiveness of oral cholera vaccine in an urban endemic setting in Bangladesh: a cluster randomised open-label trial. Lancet. 2015;386(10001):1362-71.

12. Sur D, et al. Efficacy and safety of a modified killed-whole-cell oral cholera vaccine in India: an interim analysis of a cluster-randomised, double-blind, placebo-controlled trial. Lancet. 2009;374(9702):1694-702.

13. Bhattacharya SK, et al. 5 year efficacy of a bivalent killed whole-cell oral cholera vaccine in Kolkata, India: a cluster-randomised, double-blind, placebo-controlled trial. Lancet Infect Dis. 2013;13(12):1050-6.

14. Sur D, et al. Efficacy of a low-cost, inactivated whole-cell oral cholera vaccine: results from 3 years of follow-up of a randomized, controlled trial. PLoS Negl Trop Dis. 2011;5(10):e1289.

15. WHO, Weekly epidemiological record. 2017. 34 (92): p. 477-500.

16. Hashim R, et al. Safety of the recombinant cholera toxin B subunit, killed whole-cell (rBS-WC) oral cholera vaccine in pregnancy. PLoS Negl Trop Dis. 2012;6(7):e1743

17. Grout $L$, et al. Pregnancy outcomes after a mass vaccination campaign with an oral cholera vaccine in Guinea: a retrospective cohort study. PLoS Negl Trop Dis. 2015:9(12):e0004274.

18. Khan Al, et al. Safety of the oral cholera vaccine in pregnancy: retrospective findings from a subgroup following mass vaccination campaign in Dhaka, Bangladesh. Vaccine. 2017;35(11):1538-43.

19. Ali M, et al. Safety of a killed oral cholera vaccine (Shanchol) in pregnant women in Malawi: an observational cohort study. Lancet Infect Dis. 2017; 17(5):538-44.

20. Qadri F, et al. Efficacy of a single-dose, inactivated oral cholera vaccine in Bangladesh. N Engl J Med. 2016;374(18):1723-32.

21. DaVanzo J, et al. Effects of interpregnancy interval and outcome of the preceding pregnancy on pregnancy outcomes in Matlab, Bangladesh. BJOG Int J Obstet Gynaecol. 2007;114(9):1079-87.

22. Wang $\mathrm{H}$, et al. Global, regional, national, and selected subnational levels of stillbirths, neonatal, infant, and under-5 mortality, 1980-2015: a systematic analysis for the Global Burden of Disease Study 2015. Lancet. 2016; 388(10053):1725-74

23. Peduzzi $P$, et al. A simulation study of the number of events per variable in logistic regression analysis. J Clin Epidemiol. 1996;49(12):1373-9.

24. STOPCHOLERA, Cholera and the use of OCV in pregant women. 2016.

25. Shamim AA, et al. First-trimester plasma tocopherols are associated with risk of miscarriage in rural Bangladesh. Am J Clin Nutr. 2015;101(2):294-301.

26. Taksande A, et al. Congenital malformations at birth in Central India: a rural medical college hospital based data. Indian J Hum Genet. 2010;16(3):159.

27. Sur DK, Wallis DH, O'Connell TX. Vaccinations in pregnancy. Am Fam Physician. 2003;68(2):299-304.

28. Clemens JD, et al. Field trial of oral cholera vaccines in Bangladesh: results from three-year follow-up. Lancet. 1990;335(8684):270-3.

Ready to submit your research? Choose BMC and benefit from:

- fast, convenient online submission

- thorough peer review by experienced researchers in your field

- rapid publication on acceptance

- support for research data, including large and complex data types

- gold Open Access which fosters wider collaboration and increased citations

- maximum visibility for your research: over $100 \mathrm{M}$ website views per year

At $\mathrm{BMC}$, research is always in progress.

Learn more biomedcentral.com/submissions 